\title{
Algunos documentos del Virrey La Serna
}

DOI DANIEL VALCARCEI.

\section{IINTRODUCCIOIN}

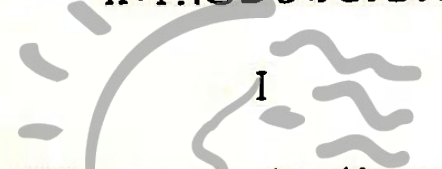

El Cusco fué paradóitcamente la última Capital del Virreinaio del Peri. Luego del Virrey don José de la Serna e Hinojosa, vino el noninal, ine étivo y fugacísima mandalo de don Pio Tristán, como ol coicfón de una épocia ya concluída.

La historia de! Perú después diel pronunciamiento de Aznapuquio y la deposición de Pezuela, há sido estudiada de preferencia en lo que

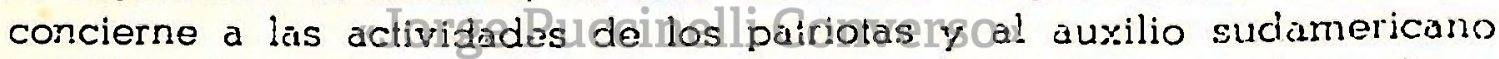
recibido. Por esto, la mayor parte de la investigación se refiere al gobierno protectoral de San Märtin, a los iniciales y convulsos momentos de la Junta Gubenativa, do José Mariano de la Riva $\Lambda$ güero, de José Tagle Marqués de Torre Tagle y de la dictadura de Bolivar. Sin embargo, para comprender la totalidad de aquel momento histórico, hacíase necesario estudiar con detención el período de Pezuela $y$, de manera urgente, el poco conocido y subvalorado gobierno del Virrey La Serna, cuya sede, como se sabe, fué la autóctona ciudad del Cusco. La cooperación de sus principales subordinados: Canterac, Ramírez, Valdez y Olañeta, le permitió dominar en Huancayo, Arequipa y el Alto Perú, desarrollando un plan defensivo y ofensivo que es necesario conocer en forma precisa y clara.

Un estudio minucioso de las actividades política y militar del último Virrey, puede explicar en parte los motivos de aquellos famosos descalabros del inicial Perú independiente y reconstruir el plan de acción realista, en forma detallada, para comprender sus éxitos obtenidos en 
siluáciones al parecer desesperadas. A este propósito está dirigida la publicación de las 83 Comunicaciones, firmádas la mayor parte por e! Virrey La Serna, desde el Cusco y Yucay, y dirigidas al Subdelegacio de Andahuaylas.

II

Entre les papeles inéditos del Archivo histórico del Cusco, cuya sedo encuéntrase en la Universidad Nacional de San Antonio de dicha Ciudad, existen cuatro Legajos, conteniendo un total de 83 comunicaciones. que ván desde el 14 de diciembre de 1821 hasta el 28 de noviemb:e de 1823. tirmadás en su casi totalidad, por el virrey don José de La Serna y que remite a! Subdelegado del Partido de Andahuaylas y Comandante del Regimiento de Milicias, teniente-coronel don Tadeo Secuura. Otras comunicaciones están a nombre del Subdelegado Interino dé! mismo Partido. Las resfantes son: del general Canterac al Jefe político de Huamanga, del Subdelegado de Andahuaylas, don Tadeo Segura; y de don Mariano de Olavarriela. Finalmente, existe un Itinerario de la ruta a seguir, desde el Cusco hasta Huancayo, por los batallones Gerona y Centro.

La distribución externa de los mencionados documentos, está hecha de la siguiente manera. L.EGAJO I: Consta de 17 comunicaciones, remitidas por la Serna al Subdelegado de Andahuaylas, son las signadas

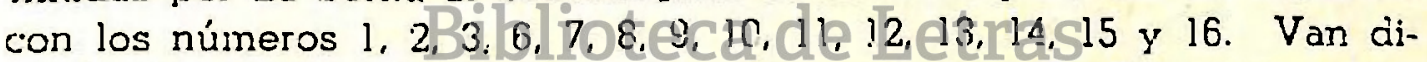
rigidas al Subdelegado Intering las número 4,5, y 17 . Muestran anotación marginal, las comunicacicnes números 1,3 y 5 . LEGAJO II. Consta de 34 comuricaciones. Son del Virrey al Subdelegado de Andahuaylas, las números $1,2,3,6,7,8,9,10,12,13,16,17,19,20,21,22,23$, $24,25,26,27,28,29,30$ y 31 . Las quie remite al Subdelegado Interino están signadas con los núrneros $4,5,11,15$ y 18 . La número 14 es del Virtey al Comandante Militar de Andahuaylas. La número 32 es remitida por Canterac al Jefe político de Huamanga, don Gabriel Herboso. La número 33 está suscrita por el Subdelegado don Tadeo Segura y la refrenda el Jefo político de Huamanła. La número 34 la firma en Andahuaylas don Mariano de Olavarticta y envíala al Subdelegado de dicho Partido. Llevan anctación marginal, las comunicaciones número 1,4 , $5,6,7,8,9,10,11,13,14,15,16,17,13,19,21,22$ y 30 . LEGAJO III. Consta de 23 comunicaciones. Están dirigidas por el Virrey al Subdelegado de Andahuaylas las números 1, 2, 3, 4, 5, 6, 7, 8, 9, 10, 12, 13, $14,15,16,17,18,19,20,21,22$ y.23. La número 11 es del Virrey al Sujodelegado Interinc de ese Pariido. Llcvan anotación marginal, las co. 
run:caciones numero e, IE y 19. LEGAlO lV. Corsta de 9 comlunca. cionez. Son jel Virey d: Subjelegerio de Andanuaylas das númo:o 1 , 2. 2. 4. 5. 6. 7 y 8. E! dcoumento : ume:s 9 es un limesurio solare la : Lie Cisco-Huncayo, que debia: seguir los balallones Gerond y Cen::0. rubricadrs por don Eulogio de Sarila Crus.

La versión dosumenial, que a coninuacion se publica, ha sido co.

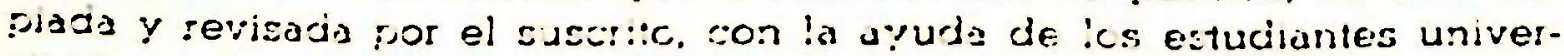
siarios señores: G. Vergara, J. Veliz, D. Herrera y L. Anglas, en el Archivo hislćrco dei Cusco. Tergo que agradecer. nuy especialmonte d! Recto: de 'a Universidad de! Cusic. jr. don josé Gabrioi Costo, po: las faclidades que me ha brindado en todo mo:nento.. Para una mefor utilización de los te\%tos, dichas Cosiunicaciones se publican crono. ójicarnenie ordenajas. poniéndose en la purte inferior de: documento sendos paréntesis dentro de los cuales señálase el Legajo y el nuimero del documento.

\section{Daniel Volcárcel.}

\section{LOS DOCUMENTOS}

Al capitan del Batallon de Eurgos D. Domingo Fermandez Deicgado que por su actual enfermedad no puede seguir là mârcha que bá á emprender dicho cuerpo le acudirá $V$. mensualmente con el completo haber De su empleo que es el de Ochenta y Un pesos; entendiendose el págo desde primero del próximo mes de Enero y solamente por el elempo que permanezca aquil entermo, pasando onortunamente el cargo de lo que recibiese al expresádelBatallon eparansu debido conocimiento.

Dios guarde a V. m. a. Andahuailas 14 de Diciembre de 1821 .

Sr. Subdelegado del Partido de Andahuailas.

(fdo.) José de la Serma

(una rúbrica)
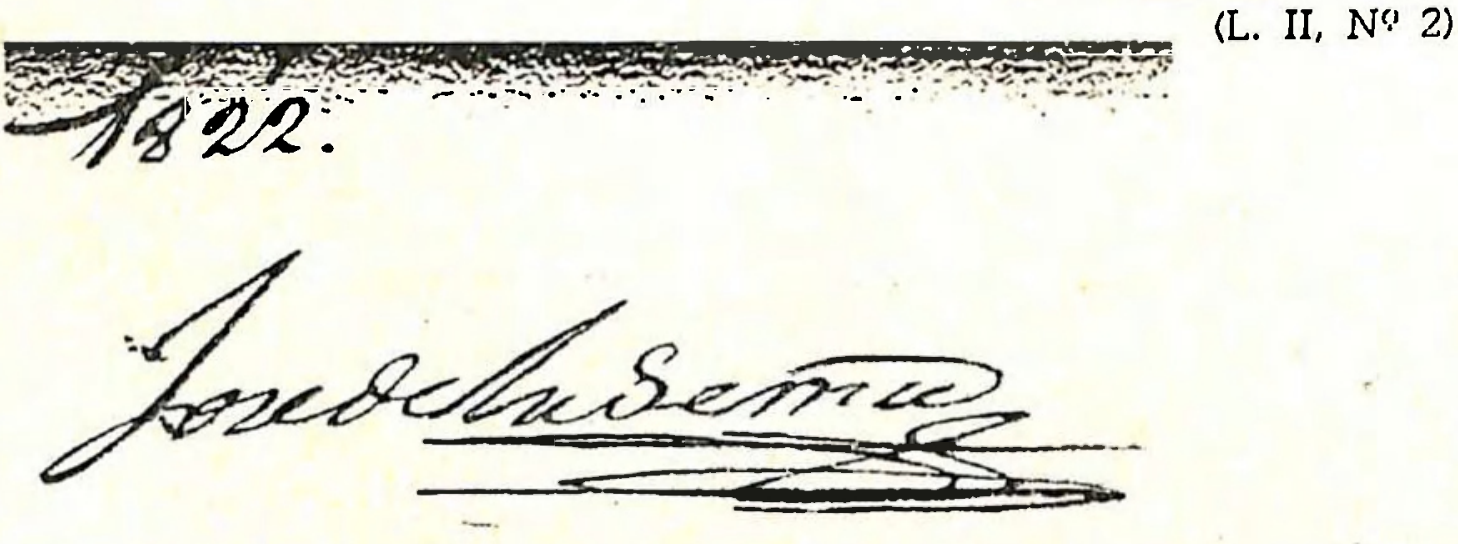
Virrey del Perú.

Si estubiesen en disposicion de caminar los tres cavallos dos castaños oscuros y el otro alasin tuerto, rue de la Compañia de mi Guardia quedaron en esa, ó quando lo esteil dispondra $V$. que en la prlmera oportunidad secura se remitan a ésta ciudad.

Dios guàrde a V. m. a. Cuzco Fnero 17 de 1822.

S.. Subdelegado dn. Tadeo Segura.

\section{(fdo.) José de la Serna}

(una rúbrica!

$$
\text { (L. II, No 1) }
$$

En la instancia que sigue el pretendido heredero del finado Cura de Huancarama Li. Necochea ha pedido el Sr. Fiscal de esta Excelentisima Audiencia los antecedentes de la materia, y en consecuencia me rernitira $V$. todos los autos obrados desde el fallecimiento del estado expresandome en el oficio a remisión cuantos sepa y concsca plieda esie venir a li. meior instrucción de dicho Sr. Fiscal, pues estoi enterado esta $V$. completmente instruido de gúanlo ocurrio ai dicho fallecimiento $y$ posieriormente.

Dios./que. á V. m. a. Cuzco Marzo 10 de 1822.

Sr. Subdielegado de Andahuailas.

(f́do.) José de la Serna

(una rúbrica)

Contextado el 9 de marzo.

(L. II, NO 3)

Me abisará $V$. "sin hẩ existido, é lisi existen Sen" ese punto las Cincuenta mulas coniratadas con Yndacochea que dispuse se situasen en ese punto, y si han servido ó sirven pars la conducsion de los contingentes de dinero y efectos. Tome $V$. un prolijo conocimiento de este asunto, $y$ abiseme el resultado sin perdida de tiempo.

Lios. gue á V. m. a. Cuzco lo de Márzo de 1822.

Sr. Subdelegado Interino de Andahuailas.

$$
\begin{gathered}
\text { (fdo.) José de la Serna } \\
\text { (una rúbrica) }
\end{gathered}
$$

$$
\text { (L. II, No 4) }
$$

Virrey de! Perú.

Procurará V. por todos los medios que le sean dables, de acuercio con el Coi:andante Militar de ese punto averisuar la situación del Toniente Coronel graduado Aballe y comunicarme inmediatamente les noticias que adquiere de él.

Los adjuntos Pliegos los hará V. continuar inmediatamente por extraordinario en toda diligencia, a Huamanga dandome aviso del dia 
dE su remistciz que será sin perdida de monentos y por è morilo alte considie:e mas seguro y pronto.

El cabo conducior podrá permanecer e: ese punic d..gunos dia : ar si hubiese resultados de Aba!le o cígun ot:o pliego interesante que traer: ba satisischio del importe de las postas de isis $\gamma$ ruelia.

Dios. gue á V. m. a. Cizzoo 6 de Marzo de 1822 .

S.. Subdelegado Interino de Andahuailas.

licio.) Jasé de la Serna

(una rúbrica'

(L. II, N": 5)

Contextado el 24 de dhoi.

A. momento des entrega: a V. el Capitan Graduado D. Francisco Maia del Vále dador de este, un pliego para el Señor Brizadier D. Iosé Carralatá recidente en fivamanga. lo dirijirá $V$. sin la menor dilacion con persona de tcda confianza jara que lo entresue al expresado Señor Brigadier, el que dará recibo de habe:lo entiesuclo y me lo remitirá V. El que lo lleve no debe tardor descle ese pinto a Huamanga mas que quatro dias, pues asi combiene.

Dios. gue á V. rn. a. Cuzco Marzo 14 cie 1822.

Sr. Subdelegado de Andahuáilas.

$$
\begin{aligned}
& \text { Biblioteca dedo.ylosé de la Serno } \\
& \text { "Jorge Puccinelli Conversou rúbrica) } \\
& \text { (L. II, No 6) }
\end{aligned}
$$

Virrey del Perú.

Contextado el 24 del rnismo.

Son adjuntas seismedia filiaciones respectivas á otros tantos ciesertores del ler. Bátallon del Regimiento de Ynfantería de Burgos, los quales siendo correspondientes a ese partido circulará V. desde luego las mas egecutivas y terminantes ordenes para que con el mayor empeño se les persiga y aprenda, ofreciendo ocho pesos por la captura de cada uno de los espresados descrtores, y al que se aprendiese lo remitirá $V$. bien Asegurado a ésta capital.

Dios. gue. á V. m. a. Cuzco y Marzo 15 de 1822.

Sr. Subdelegado de $\AA_{\text {ndahuailas. }}$

(fdo.) José de la Serna

(una rúbrica)

$$
\text { (L. II, No 7) }
$$


Virrey del Perú.

Al conducior de! presente extraordinario le he mandado entregar dos pliegos una para el Sr. Coronel Rodil y otro para el Comandante del Escuadrón de Dragones de Lima con orden de que si los encontrase en su tránsito hasta ese punto los entregue manifestando á V. los ro cibos respectivos y de nó que los ponga en poder de V. En este concepto si el citado conductor entregase a V. los citados pliegos los entregerá $V$. en el acto a sus rotulos si los interesados estubiesen en ese punto, y si ya hubieren regresado á Huamanga y el $2^{\circ}$ con el Essuadron de su mando que es como debe hacerlo, en este caso me devolverá dichos pliegos, Dandome Åviso de todas maneras del resultado.

Dios. que. á V. m. a. Cuzco 16 de Marzo de 1822.

Sr. Subdelegado de Andahuailas.

(ido.) José de la Serna

(una rúbrica)

Virrey del Perú.

Contextado.

(L. II, No 8)

Si el Escuadron de Dragones de Lima estubiese á un en ese doy orden á su Comandante que en el momento regrese para Huamanga y lo mismo le ordeno lo verifique descie el punto en que resiva $\mathrm{mi}$ orden. En este concepto bien sea que el citado Comandante reciva la expresada orden en camino mas aca de ese pueblo óahí mismo despachará V. inmediatamente por extraordinario Cen $\ell$ bl modo que conceptuan mas seguro y pronto, el adjunto pliego al Señor Brigadier Carratalá, avisandole V. el punto en que este conductor encontrase en su transito al mencionado Escuadron, en caso de que.así sucediere; pero si ya este Escuadron hubiese verificado su marcha para Huamanga desde ese punto antes que $V$. reciva el presente, entonces remitirá el pliego adjunto por el Correo.

Dios. gue. á V. m. a. Cuzco Míarzo 16 de 1822.

Sr. Subdelegado de Andahuailas.

(fdo.) José de la Serna

(una rúbrica)

$$
\text { a. II, N? 9) }
$$

Virrey dè Perú.

Contextado el 24 del mismo.

Si como supongo, hubiese ya pasado de ese punto para San Juan de Lucamàs el Capitan D. Francisco María del Valle que hayer salió de 
est: Capital con pliezos paru el S. Briqadier D. Geronimo Valdos, dispendra $V$. inmediatamente la remisión del adjunto al Teniente Co:one! graduacio D. Cayetano Aballe a crien encurgará lo hacia pusar al rexpre. sado S. Vúldies, con conduetor de kido contianzs, prersiniendo al citado fibelle, quo :emila, recivo que actedite que dicho Gele ha recivido ol citacio acjunto pliego.

Dic:. gue. à $\vee$. n. a. Cuzcc Marzo le de 1822.

SI. Subdeiergado de Arrdiahuailas.

itclo. losé de la Sorna

(una rúoricos)

(L. II, $N: 101$

El Excelentisimo Sir. Virrey en oficio de 6 del pasado me dice lo siguiente. "Dispondrí $V$. S. que todos lo: productes de los fondos, fincas sq que se reconocen en les provincias de su mándo, propjos de Casa de Comunidad, ó de particulares tahto Seculares como E!esiastices, rosidentes en la Capital de Limá ó en el poságe ccupado por los enemigos. ingresen en la Tescreria Nicional del Distrito a que coresponda en clase de depósito, franqueandose a quienos corresponda por los S. S. Mi nistros de Hacienda publica las respectivas certificaciones. Esto medida no solo consulta el reunirse fondos para tás actuales urgencias del Erario Nacional, sino que la exioe el dicho de reprocidad en vista de la conducta que han observacio los invasores respeclo á los bienes de los que han inmigrado de Lind, pero guiadJ grenpre de las ideas cie! Supreino Gobierno de la Nación, serín reintegrados sus dueños por la misma Hacienda luego que las armas Nücionales restablescan el orden. siempre quie la conducia política de aquellos no haya sido criminal. De las cantidades que consiguientemente á esta Disposición Deben ingresar en Caxas Nacionales me dará V. S. una noticia circunstanciada, y desde luego servirá dar las ordenes correspondientes para que en cacla provincia se haga una prolija averiguación de otros fondos, y que los enteros se verifiquen con la brevedad que demandan las necesidados del dia. La noticia circunstanciacla que debe darme V. S. de las cantidades que deben ingresar en las Caxas llacionales, comprenderá también la denominación particular de las fincas, fondos, su cituacion $y$ el nombre de sus poseedores, arrendutarios, el de sus dueños delos cilados productos, y de sus apoderados o enmisionados para susesibo designando los predios reales, roditos, y dernas por menores conducentes a tener un exacto y prolijo conocim!ento de la Materia" $Y$ los trarrscribo á V. S. para su exacto cumplimiento en la parte que le co- 
rresponde, sirviendose pasarme con la brevedad que le sea posible las noticias circunstanciadas que el Excelentísimo' Sr. Virrey pide para pasarlas yó á manos de su Expresada para los fines que son consiguientes $\dot{a}$ esta delerminación - Dios guarde a V. S. m. a. Quartel general de Huancayo Marzo 22 de 1822 - José Canterac - Señor Gefe Político de la Provincia de Huamanga Dn Gabriel de Herboso" - "El Excelentísimo Señor Virey en oficio de 16 de Febrero ultimo me dice lo que sigue - Con el obgeto de que su determinación de 6 del actual fue los productos de los fondos, fincas, pertenecientes a casas de Comunidad, Cuerpos o establecimientos que conserven su intitulo, se recaudarán por el Govierno, y entraran en las Tesorerias de la Hacienda publica, y si al Gobierno constase que algunos de los Yndividuos de dichos cuerpos subsiste en la Miseria, y es acredor por su conducta á ser auxiliado, le proporcionarán los socorros que crea oportunos por los medios que estime mas propios; cuydando tambien que de las renias que recauden pertenecientes a dichas Casas de Comunidad, Cuerpos, y establecimientos, se provea a la mantencion de aquellos Yndividuos, que siendo participes de las mismas corporaciones, y han abandonado sus hogares, por no estar bajo la dominación enemiga, vivan en Pais libre, según su estado, y carescan de otros medios de Subsistencia, entendiendose esta resolución extensiva tamvien a los particulares - Y lo comunico a V. S. a lin de que la haga circular, y publicar por las Provincias de su inmediato mando Ca que transcribo á V. S. para su inteligencia y cumplimientoe enula coartelque le corresponda, dandome aviso de ello - Dios guarde a V. S. m. a. Quartel general de Huancayo. Marzo 22 de 1822.

(fdo.) José Canterac,

Señor Dn. Gabriel Herboso Gefe Político de la Provincia de Huamanga.

Es copia. (fdo.) Herboso.

Contextado en 9 de marzo.

Para precaver y remediar los abusos qus me indica $V$. en su oficio número 24 paso orden con esta dicha a ese comandante Militar a fin de que haga cumplir lo que manden los pasaportes y que a todo intractor lo ponga preso y me dé parte. $V$. debe darmelo tambien de qualesquiera que cometiere tropelia en las postas y pueblos de su jurisdiccion, pues de otro modo, ingnorando quienes son los delincuentes, no es posible castigar los delitos. 
Me remitira $\%$ una reiaction execta veridica de lodos iquellos a quienes ies hayan quitido bestics con ess:asica de sl vaior paro conciliar el modo de reearcir es este, hactendo $V$. saber a lodos los abitiantes

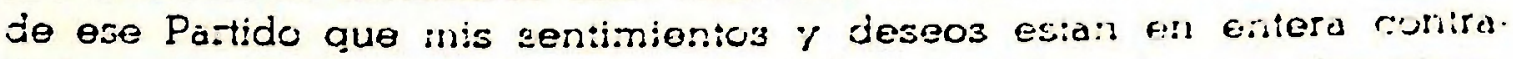
dicion cen este y qualquiera oira c'uso de perjuicios que expertmentuse, y gue siempre me encontrard pronto i propender a sid ternedio y is proporcioniries cisnios bonelicio" me seur posiblst.

Eios. gue. a $\because$ r. r. d. Cuzco 30 de inazo de 1822 .

Si. Subjelezädo Inıerno de Andahuailas.

$$
\begin{aligned}
& \text { (ido.) Iosé die la Serno } \\
& \text { (cina rubrica) } \\
& \text { (L. II, N: II) }
\end{aligned}
$$

Por su oficio 24 del gue vá á efpirer quedo impussto del juvilo que le ha cavidio por el Superior mando ce estcs Reinos cuo me he confiado 3 . M. Doy á $\forall$. lás más expresibas gracias: y no dudo que en su de cidicia adhesion por la justa. causa quo defienden las armas Nacionáles, será tan constante que coadyuvara del modo más pá!pablo al logro de su grande objeto.

Dios. que. á V.m. a. Cuzco Marzo 30 de 9822.

A. D. Tadeo Segura Toulente corone!verSO»

y Sutdelegado del Partido de Andanualàs.

$$
\text { (fdo.) José de la Serna }
$$

(una rúbrica)

$$
\text { (L.. 11, N? 12) }
$$

\section{Contextado.}

Impuesto de lo cque $V$. me comunica en sa of:cio num. 28 incluyendo perles que desde e! camino pura chincheros le dirijio cl Cornandanto Militar de ese Partido Dn. Pedro de la Peña, he dispuesto cque on el dia de mañana salga do acqui el Comanciante Horna con el Esquádron de Árequipa de su mando, y suponiendo cue el citado Peña había márchado para Huamanga en virtud de la aiden de aquel Jefe Político y Comandante Militar prevengo a $\mathrm{V}$. que los noventa y quatro recuitas conducidos por el Cüpitan Dn. Rafael Sarmiento que salieron de esta el dia 2 del actual se retengan en ese pueblo bien custodiados por $\mathrm{Mi}-$ lícianos y Paysanos honrados de el, tomando V. para ello quantas me- 
didas y precauciones estime convenientes, y que el espresado Sarmiento con los Treinia y dos hombres que llevo de escolla no pase a Pampachiri sino que aguarde a que llegue el mencionado Comandante Horna.

Dispondra $V$. que en el acto se le tome al P. Fray Bernardo Arechaga y al Subdelegado Dn. José Joaquin Pasayllo una declaración circunstanciadia de todo lo que hubiese ocurrido en Cangallo, de quien Q.s, o son los que han hecho cabeza, que gente se había reunido, con que armas, acionde se dirigian, de que pueblos, que motivos tubieron para este alboroto y me remitira dicha declaración.

Tcodas las cargas que estaban en camino para Huamanga y han regresado se detendrán en esa con la sejuridad correspondiente, hasta tanto que se halle franco el camino y puedan conlinuar como se ha hecho hasta ahora con escolta.

De quantas noticias interesantes, pueda $V$. adquirir de los rebeldes cangallinos y de Huamanga me dará parle inmediatamente, y desde luego embiara esploradores de toda confianza $Y$ verdad que se instruyan de ellos.

Dios guarde a V. m. a. Cutco 10 de Abril de 1822.

Al Sr. Subdelegado del Partido de Andahuailas. -ído.) José de la Serna

\section{Biblioteca de Letras rúbrica) \\ "Jorge Puccinelli Converso"}

Mi ayudante de campo el Teniente Coronel graduado don Jasé Manuel Vigil pasa a ese punto a llenar la comisión que se espresa en las Ynstrucciones que le ha dado y manifestado á $V$.

Si al recivo de esle hubiesen yá desaparecido los Morochucos nuevamente, sublevados, y estuviesen espedito el carnino hará V. continuar inmediatamente y a Huamanga los reclutas y demas cargas.

Dios. gue. á V. m. as. Cuzco abril 10, 1822. (fdo.) José de la Serna (una rúbrica)

Sr. Subdelegado de Andahuailas. (L. I, No 2)

Contextado.

Con el oficio de V. numero 37 he recivido el Pliego que me incluye del Sr. Gefe Politico de esa Provincia. 
Quedio enterado de que $h a$ despachado a la Parte del Parlido de Vilcashiaman en averiguacion de los norimientcs que hay sa el, y espe:o rie comunique su resultado.

Está bien gute interindmer:'e no re aclare la coniucion que hay do noticias de enemigos for las inmedinciones de Husnamja, detenga $\forall$. en eze punto a! Japitan Simienlo con sl particia y a mi Ayudanto Se Campo el Teniente Cororel Vicjil a cuien dira $V$. en mi nombre ba. ya hasia ei Funto de Pampiss y quo con arreglo a mis instruccionos nie de un parte citral de lo que hibiese ocuirido $\gamma$ noticias veridicas que adquilera.

Reencargo a $V$. muy micho la seguridad que deve consultarse en los reclutas $y$ de lás cargas del Servicio Nacional que hubiesen quedado en ese punic, avisando las que sean, y aclarandome en donde es cionde dejó los contingentes el conriuctor del Plierjo que me dise.

Dios. gue. a V. m. a. Cuzco 17 de A.bril de 1822.

(fdo.) José de la Serna

Sr. Subdelegado de Andaguailas.

(una rúbrica)

Contextado.

(L. II, N!3)

Si todas las mulas del Asentista Miranda hubiesen caminado para Huarränga con el contigente, proporcionará Ud. desde luego las correspondientes á nueve cargas que en el dia de mañana saldran de aqui para Huamanga adonde deberân pasar con la misma escolta que condusca los Reclutas gue enCficiol he pdsado 'digo a Ud. que tambien saldran mañana. Para que ni aquellas ni estas se delengan en ese punto prevengo a Ud. que en el caso de que aun no hubiese Regresado el Teniente Coronel Graduado Peña con la fuerza con que fue escoltanto el contingente, baya escoltando dichas y Reclutas la restante do la compañia de aquel que ha quedado en ese punto encargando V. en mi nombre al oficia! que baya de comandante de ello la doble vigilancia que debe tener con los Reclutas por razón del cuidado que exigen las cargas de dinero.

Para que ese punto no quede sin guarnicion en el expresado caso de que tenga que salir la fuerza actual que hay en el; ordeno con esta fecha al Capitan Dn Rafael Sarmiento que en el acto que reciba mi orden adjunta que le dirigira $V$. por Otra orden se ponga en marcha con la fuerza que tiene a su mando para ese pueblo, en donde permanecera hasta tanto que vuelva la que salga con dichos reclutas, $y$ entonces si no hubiese que traer prisioneros se vendra a esta capital. 
Ml Soñor Jeĺe Politico de esa Provincia dará V. parle por estraordinario de la remesa de los reclutas y cargas para que envie la essolta competente oue en el camino releve la de ese punto. y que le avise inmesiatamente si remite ó nó prisioneros para que con este conocimiento se detenga ó no e! Capitan Sarmiento y partida que ba con dichos reclutas los cuales descansaran e: ese punto solamente tres dias, esto es si tuviese noticia que en este termino pueda liegar ei Teniente Coronel Peña si aun no hubiese regresado pues de lo contrario no desconsaran mas que uno.

Las expresadas nueve cargas ban pagadas de sus fletes hasta ese punto y ademas de las mulas para ellas, aprontará $V$. una mas de carga y otra de silla para el conductor: reservara V. la noticia de que ba dinero pues nunca es bueno que se sepa con anticipacion.

Si los Dos cientos treinta que remite para que pasasen a Huamanga no hubiesen caminado se retendran en ese punto sin abrir los cajones on que estan dandome aviso.

Dios. gue. á V. m. a. Cuzco 7 de Mayo de 1822.

$$
\begin{gathered}
\text { (fdo.) José de la Serna } \\
\text { (una rúbrica) }
\end{gathered}
$$

Sr. Subdelegado da Andaguailas.

$$
\text { Biblioteca de Letras (L. I, N! 3) }
$$

En el dia de mañana saldran de esta Capital con destino al ejercito de Lima 194 reclutas y 18 ynvalidos y anticipo a $v$. este aviso para su conocimiento.

Si al regresar de Huamanga el Comandante Militar de ese punto trajese algunos prisioneros con destino á esta Capital, los escoltara la partida que va ahora con los recluias y la del Capitan Sarmiento quie esta en Pampachiri en caso de que por no ser necesaria en aquel punto, regrese á esta Capital.

A los adjuntos pliegos para Pampachiri y Huamanga dara V. inmedialamente Direccion por extraordinario.

Dios. gue. a V. ms. as. Cuzco, Mayo 7 de 1822.

$$
\begin{aligned}
& \text { (fdo.) José de la Serna } \\
& \text { (una rúbrica) }
\end{aligned}
$$

Sr. Subdelegado interino de Andaguailas. 
Contextado.

Tengo a la vista los siete oficios de $V$. numeros 48 a 54 y en su contestacion le diré.

Que recibi los pliegos de que en ellas me hace mencion.

Que el Comandante Genera! Militar de esa Provincia remite en esa lecha la carta original jel cura Dr. Riosas para que desde luego disponga lo conveniente a la cons:ante persecucion del Cabecilla Quiroz a fin de que ni puedia ongrosar los restos con que escapo de la derrcia que sufrio por el Sr. Brigacier Carratalá ni tenga en continuo subsidio a los buenos servidores.

Que quedo enterado de que en las mulas del Asentista Miranda continuarian a huamanga las nueve cargas de que le hable en $\mathrm{mi}$ oficio cie siete del corriente y de lo demas que me relaciona en el suyo numero 52.

Que por la rázon que me incluye en el numero 51 veo que son 274 pesos 6 l| 2 rs. los suministrados del ramo de la unica contribucion de su cargo para e! socorro á razón de 1 1|2 reales diarios por plaza a los 92 reclutas que estuvieron detenidos en ese pueblo desdo 20 de abril hasta 5 del actual.

$Y$ que esta bien que luejo que regreser de Huamanga las mulas del Asentista Miranda les pasara la revista que le he encargado y me remitira la certificacion en los terminos que le he prevenido.

El Capitan Sarmiento me dice con Gecha 4 del presente la necesidad que tenia de dinero para csocorrer la tropasde su mando mas creo que á los pocos dias le seria cubierta por $V$. con la remesa que al efecto le hizo en primero del mismo este Sor. Comandante General y desde luego me avisara si se la Dirigio al citado Sarmiento y en que cantidad iria avisandome lo que sepa del movimiento que hizo este oficial sobre el caudillo Quiroz.

Dios gue. a V. m. a. Cuzco Mayo 17 de 1822.

(ido.) José de la Serna (una rúbrica)

Sor. Subdelegado interino de Andaguailas.

(L. I, N? 5)

Quedo enterado que al hojalatero Rafael Barrios le dio V. doce pesos para continuase su viaje a Huancayo, los cuales puede cargar en 
las cuentas de la unica contribucion de su cargo con lo que contesto a su oficio No 59 .

Dios gue. a V. ms. as. Cuzco Mayo 31 de 1822.

Sr. Subdelegado del partido de Ändaguailas.

$$
\begin{aligned}
& \text { (fdo.) José de la Serna } \\
& \text { (una rúbrica) }
\end{aligned}
$$

$$
\text { (L. I, N०6) }
$$

Se han recibido los dos caballos do la Compañia de mi guarnicion que quedaron en esa, y quedo enterado que en la mantencion de ellos desde el 15 de diciembre hasta 21 del presente ha invertido cuarentainuebe pesos Seis reales los quales puede V. cargarlos a la unica contribucion del partido de su cargo, con lo que contesto a su oficio 61 .

Dios que. a V. m. a. Cuzco Mayc 3!/-1822.

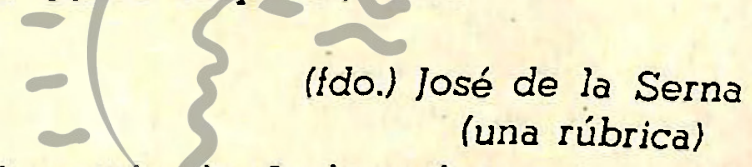

Sr. Subdelegado del partido de Andaguailas.

$$
\text { (una rúbrica) }
$$

$$
\text { (L. I, No 7) }
$$

Quedo enterado que las mulas del Ásentista Miranda salieron de ese punto el 20 del Corriente Conduciendo las Nuebe cargas de dinero con destino al eiersito de Lima en Huancayo y que igualmente salieron los reclutas que habia en esa, y que expresan los prisioneros el Capitan Sarmiento y el de igual clase Hurtado para conducirlos á esta. Con lo que conteste a su oficio No 56 .

Dios guarde à V. m. a. Cuzco màyo $31 / 822$.

$$
\begin{gathered}
\text { (fdo.) José de la Serna } \\
\text { (una rúbrica) }
\end{gathered}
$$

Sr. Subdelegado del Partido de Andaguailas.

$$
\text { (L. I, No 8) }
$$

Contextado en 8 del mismo.

El 8 del actual seldrán de esta Capital Dos cientos Reclutas con destino al Batallon de Casadores, por lo qual descansando un dia en este punto, continuarán a Puquio, escoltados por la tropa de ese destaca- 


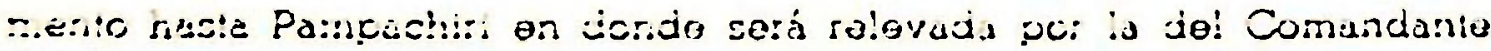
Abeile con guien al inienio se rond:' $V$. de azuerdo ct!eandole po:

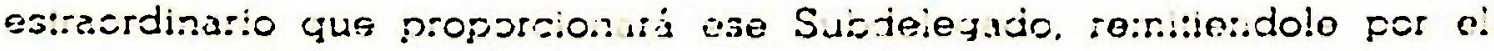
mastro el adjunto pliego.

Dios gue. à V. m. à Juzco. s de linio $: 822$.

\section{(ido.) lasí de la Serma funa rúbrica)}

St. Comandanie lathtur do! Partido de andaguailas.

Contextado en 8 disl mismo.

Los azogues que de ciuenia dr la ildrisncis Nucional supongo yá en ese punto procedenies do Huancavelica los remitirá V. á esta Capital !eter:do pata ejlo lás mulas oorrespondientes, haciendo que se aten bien las bidanas, repesando iodos los atados, poniendo badanas nuevas a los que las necesiten $y$ arisandome si es nocesario se remitan esias cle aqui y esantas, encargando la conduccion do otros azogues á una persona de conlianza que renca al cuidado de ollos para que los arrieros no los roben haciendo sid entrega por pesos.

D:os gue. a V.Tri.ja. Cuzco dulio 5 de 1822.

\section{"Jorge Puccinelli Cado.erosé de la Serna} (una rúbrica)

Sr. Subdelegado Interino do Andahuailas.

(L. II, N! I5)

Coniextado en 8 del mismo.

El 8 del actual saldrán deesta Capital cios cientos reclutas que pasaran desde ese punto á Puquio, y anticipo á V. este aviso para que desde luego dé las providencias conbenientes á los pueblos del transito respectivos a su jurisdiccion a fin de que apronten los víveres necesarios que serán pagados por aquellos y la escolta á sus justos precios, a excepción de la Leña y sal que son articulos de obligación de los pueblos, como asi mismo el proporcionar los Calderos ú ollas competentes para hacer los ranchos, franquiar (sic) alojamientos para la custodia y demás que es de costumbre.

Tan luego tendrá V. prontas diez mulas de carga y una de Silla para lo que saldrá en estos dias para Uumanga. 
A. Comandante Militar de ese punto proporcionara V. en el acto de resivir el prasente un estraordinario de confiansa que condusca ur. pliego al Comandante A.balle de Lucanas.

Dícs gue. á V. m. a. Cuzco 5 de Julio de 1822.

(fdo.) José de la Serna

(una rúbrica)

Sr. Subdelegado de Andahuailas.

(L. II, N! 16)

Contextado en 8 del mismo.

Remitame V. una noticia de lo que hán importado los fletes de las nueve Cargas de Plata conducidas por Dn. Vizente Rodriguez y la mula de Silla que ociupó esté, y los quales me dize en su oficio numero 66. haber satisfecho de los londos de su cargo, y que lo mismo hiba á hacér con las Treinta Cargas que menciona en dicho oficio por haberle manifestado el peon comisionado del asentista Dn. Roque Miranda la imposibilidad en que se hallaban sus mulas; por lo que el importe de los espresados fletes se han de descontar de lo que devengan las mulas de dicho Asentista Miranda, á quien hará V. sabér que su contrata terminó a fin del proximo pasado Junio $y$ que solamente continua (ilegible) en terminos que sean más bentajosos á la (ilegible) Su resultado me avisará lV para determinar loconbeniente.

Dios gue. á VJm.ga Guzcon 5 dedulio des $18,22$.

$$
\begin{gathered}
\text { (ído.) José de la Serna } \\
\text { (una rúbrica) }
\end{gathered}
$$

Sr. Subdelegado de Andahuailas.

$$
\text { (L. II, No 17) }
$$

Contextado en 8 del mismo.

El adjunto pliego para el Sr. Gefe Político de esa Provincia y una encomienda rotulada al Sr. General Canterac ạue lleva el Conductor del presente Dispondrá $V$. que por. un extraordinario continuen para Huamanga dandome aviso de haberlo asi verificado.

Dios gue. á V. m. a. Cuzco, Julio 5 de 1822.

(fdo.) José de la Serna

(una rúbrica)

Sr. Subdelegado Interino de Andahuailas. 
Coritextadio en 7 de Ágro.

Tado el dinero que rsmita ; $V$. el Sijudelegado de Aymaraes lo ro :endra $V$. en su pccier sia jar.e ciestino elquno tasia que yo disponga $\epsilon$. que deba darle, y para lo quá. me sira $V$. parte de las cantidades c. $2 \theta$ recibiese.

Dios gue. is in. a. Cuzso 8 diz Juiio de 1822.

(ício.) josé de la Serna

(una rúbrica)

Sr. Suicdeiegado de Andariuailas.

(L. II, N:19)

Don Tadoo de Segura Teniente Coronel, Comandante del Regimiento de Ynfanteria de Milicias de este Parídio, y Subdelegado en ól $\&$.

Don Rafael Barcena zondu'ce silegos inportantes á los Señores Gefe Politico y Comandante general de la Piovincia; a quien los Maestros de Portada del Transito en la Guamanga le frarqquearán la cabalgadura y cuia necesarias pagando medio bor el bagage y un cuartillo al guia por legua con arregio á la ultima orden superior: Sale a las once de la noche de la fecha. Socorrido con diez y ocho piesas tres reales. Andaguaylas. Julio de 1822.

(fdo.) Tadeo de Soguräloteca de Letras (una rúbrica)

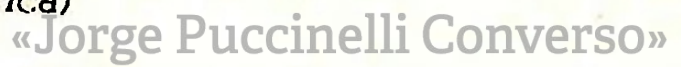

Huamanga julio 1 ! de 1822.

Se le refrenda el presento, en los rnismos terminos que ol anterior hasta Andaguaylas.

(fdo.) Herboso.

(L. II, N! 33)

En este diá salen de esla Capital 2.40 reclutas con destino al Exercito de Huäncayo y lo aviso á V. para que desde luego dé en los Pueblos del transito de su juridiccion las ordenes conbenientes para el apronto de viveres y demás nesesario segun se ha practicado en las remesas anteriores.

Dios gue. á V. m. a. Julio 12 de 1822 .

$$
\begin{gathered}
\text { (fdo.) José de la Serna } \\
\text { (una rúbrica) }
\end{gathered}
$$

Sr. Subdelegado de Andahuailas.

$$
\text { (L. II, N? 20) }
$$


Contestado por el Alcalde.

A] cargo del Cabo de Artilleria Pablo Quevedo saldrán mañana de esta Capital Catorse cargas de Polvora y una de Papel, las guales dispondrá $V$. que sin detencion pasen en mulas de ese punto á Huamanga con la competente escolta gue le franqueará ese Comandante Militar en virtud de esta orden y para lo sucesivo le servirá de regla general que todas las carasas de dinero, pertrechos, efectos de que se remitan como las presentes para el Egercito de Lima, han de continuar de ese punto para Huamanga sin detencion alguna, dandome V. siempre aviso del día de la llegada y de la salida, y a cargo de quien bayan.

Dios gue. á V. m. a. Cuzco 12 de Julio de 1822.

$$
\begin{aligned}
& \text { (tdo.) Jasé de la Serna } \\
& \text { (una rúbrica) }
\end{aligned}
$$

\section{Sr. Subdelegado de Andahuailas.}

Contextado en 7 de Aglo.

$$
\text { (L. II, No 21) }
$$

Oy han salido de esta Capital los Arrieros Manuel Gonzalez y Mariano Salas conduciendo Veinte Cargas de Bayetones, y media carga de Botones con destino a! Egercito Nacional de Lima: para quando lleguen á ese punto tendrá $Y$. prontas las mulas competentes á fin de que sin demora pasen á Huamenge ton la correspondiente escolta que le franqueará ese Comandante Militar en virtud de ista orden, y serán entregadas en Huamanga al Comisionado de dicho Egercito el Teniento Coronel Graduado Dn. Jose Miguel Bahamonde. Los arrieros bán pagados de todos sus fletes hasta ese punto, y deben precisamente llegár á el, en el termino de doze dias contados desde mañana.

De la llegada de dichias cargas y su continuación á Huamanga me dará vuestro aviso.

Dios gue. á V. m. à. Cuzco, 19 de Julio de 1822.

$$
\begin{aligned}
& \text { (fdo.) José de la Serna } \\
& \text { (una rúbrica) }
\end{aligned}
$$

Sr. Subdelegado de Andahuailas.

$$
\text { (L. 11, No 22) }
$$

El dia dos del entrante més, saldrán de esta Capital 25 cargas de eiectos con destino al Egercito de Lima, y anticipo á V. este aviso para que al efecto tenga prontas las mulas necesarias para que sin demo- 
Ia j-gura continuen su marcha a huamanga. $Y$ de haberio asi verific.: so ne dará aviso.

Dios que. à V. in. a. Cuzco 29 de figosito de 18?2.

(fdo.) losé de la Sernis

(una rúbrica)

So:. Subjelegudo jel Partido de Ándiahuaylas.

(L. I, N!: 9)

Lie :ectvjdio e! plingc que me incluye $V$. en su ofieio 1 " 79 y e! cuál le fué dirigido nor

En virtud de el Sor. Gefe Politico militar de ese Provincia

Suzor. Orden se a quieh por extruordinario dirijira V. tambien le dieron a! Exel adjunto.

träardinario Fer-

Dios gue. a V. m. as. Cuzco Sept. 3 de 182?. nando Menacho treinta y cinco pesos (tdo.) José de la Serna por la conduccion del Pliego que se (una rúbrica) expresa. Andaguaylas sept. 6 de 1222.

nando Menacino ireinta y cinco resos

(fdo.) Segura.

Sr. Subdelegado de Andahuaylas.

(L. I, N!10)

\section{Escuadrón Dragones del Perú.}

ficabo de llegar á este Puebio con pasaporte amplio del Exmo. Sor. Virrey para que se me den todos los auxilios que pueja: necesitar con objeto de conducir al Valle de Jauia lodos los efectos del expresado cuerpo por los que necesito se sirva mandar la orden al Alcalde para que me apronte veinte mulas de carga.

Dios gue. á V. m. a. Andahuailas Spre. 13 de 1822.

(f́do.) Mariano de Olavarrieta (una rúbrica)

Sor. Subdelegado del Partido de Andahuailas.
(L. II, N? 34) 
Contextado en 29 del mismo.

Con este se recibie- En este día salen de esia Capital al cargo del ron dos Pliegos de $S$. E los que se remitieron el 18 por ol Extraordinario Dn. Rafael Barcenà al que se le dió á buena cuenta de su porte veinte Capitan D. Juan I.arraz y esccita de cuatro Dragones treinta y una cargás de efeclos para el Exercito de Lima, las cuales hara V. continuar sin demora para Huamanga dando curso de allo. Dios gu. á V. m. as. Cuzco septiembre 15 de 1822 .

sinco pesos.

(fdo.) Segura

Sor. Subdelegado de Andahuaylas.

(fdo.) José de la Serna (una rúbrica)

Con techa digo al Sor. Jefe Politico é Intendente y Militar interino de esa Provincia lo que sigue "Todas las cargas que sean conducidas á esa ciudad en mulas de Andahuaylas, esio es, proporcionadas por el Subdelegado de aquel Fartido. deberan regresar precisamente de esa Ciudad, en donje proporcionará Vs. las necesarias para las que deban continuar de Huancayo siende absolutamente necesario que las mencionadas de Andahuaylas regresen á acouel punto porque de lo contrario se remonta la arriería y sufren los convoyes demoras perjudiciales por falta de aquellas. Io digo á XS, para su inteligencia y cumplimiento". $Y$ lo transcribo a $V$. en contestacion a su Oficio No 82.

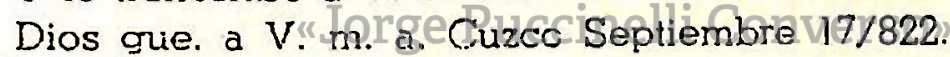

Sor. Subdelegado ds Andahuaylas.

(f́do.) José de la Serna

(una rúbrica)

(L. I. No 12)

Enterado de lo que V. me hace presente en su Oficio No 80 le dire que calcule que viveres detodas clases son los que puede proporcionaz ese Partido esto es, de ganado mayor, lanar, cabrío, y cerdoso, phpas, chuño, quinua, maíz, y ciros semejantes; hecho este calculo sabrá $\checkmark$. cuantos dias en la semana podrá darles racion de cualesquiera de dichos renglones que es decir que un día dará de carne de baca, otro de carnero, otro de cabra, otro de cerdo, otro papas, ó cualesquiera o Ira de las mienestras (sic) inciicadas en la inteligencia que no habiendo de darse a la Trops en dinero mas que un real por plaza, son por. 
io ian:o nezesartas é inte:ezartes las actones, pues de este modo es tambiér. meros el numerario que hay que exhiri.

Las aciones se arreglaran las de cistre a u:ha $\gamma$ media libra por pleza, y las de papas y demas meriestras a la ca:stidad proporcionada que $V$. acuerje con el Comur:jents je! Depos:io conun:aundome c.rcunsianciadamente cuanto convengo y arreglen en la materid y también ai Sor. Jefe Politico y Milita: Intendente de esa Provincia.

Sin periuicic del Sor. Gele Politico y Militar de esa Pronvin-.. da p:evengo en esta dicha lo conveniente para que los Portldos de. Lucenas, Parinacochas y Anco au\%ilien e V. Eacia uno de por si en la iacilitacion de viveres bajo el mismo respecio que le he expuesto para el suyo, doy disectamente la orden en es:E dicha a los Subdelegados de los primeros, esto es, Iucanas y Parinacorhas, por que desde luego empiecen a remitirlos.

Por lo que hare al de Aymarais (sic) se le pasara la orden por e: Sor, Gele Politico de esta Provincia.

Me dira V. los precios á que costarćn en ese Particio las carros y demas viveres expresados, no dudando que serán arreglados y equitalivos.

No hay necesidad tamnoco de aue todos los dias tenga pan la tropa, unos seles dära y otros no allernardo c supliendo su falta con maiz para que lo hagan cancha, mote, en el supuesto de que del real que se les dé han de pagar el pano maiz ccmo sucede aqui en el Exercito $Y$ icdas partes pues no so dá racion de pan sino que lo compra le que guiere.

Dios gue. a V. m. a. Cizzco 17 de Septiembre de 1822.

(fdo.) José de la Serna (una rúbrica)

Sor. Subdelesado de Andahuaylas.

$$
\text { (L. I. No 13) }
$$

La Compañia del Infante acantonada en ese punto se hạ repleyado a su Cuerpo de consiguiente queda expedita la contribución de ese Partido para atender á parte del entretenimiento del Deposito. En este su-. puesto digame $V$. cuanto es la cantidad a que aquella asciende, la que cada mes podrá entregar en dinero para dicho deposito, y cuales son los demas gastos que tenga que cubrir, con una noiicia bien circunstanciada de ellos, para con todos estos conocimientos arreglar y determinar lo que deva remitirse para el completo del Socorro de esas tropas. 
Todo lo que digo a $V$. en contestación a su Oficio de 15 del actual.

Dios glie. á V. m. a. Cuzco Sep. 24 de 1822.

(tdo.) José de la Serna

(una rúbrica)

Sor. Subdelegado de Andahuaylas.

(L. I, NQ 14)

Informado per el Sor. Brigadier Carratalá de que con determinacion de veinio de cctubra no puede mantenerse bien la tropa de ese deposito, determino que ademas del medio real diario se dé tambien una racion diaria de una libra de pan: dos veces a la semana racion de carne y los demas dias ce la semana racion de papas ú otra clase de menestras, haciendo para ello bastante a copio de ellas en especial de Papas. Lo digo a $V$. para su cumplimiento.

Dios gue. á V. m. a. Cuzco 5 Noviembre de 1822.

Sor. Subdelegado de Andahuailas.

(tcio.) José de la Serna

(una rúbrica)

(L. I, N? 15)

Todos los caballos y yeguas que con esia dicha ordeno a! Subdelegado de Lucanas remita a V. son destinadas para que los cuerpos de caballos que han deJpasar porcese punfocoñedestino a esia Capital, hagan uso de ellos en las marchas y traigan tirados los que les han de servir para batirse. En este suouesto V. por su parte tambien hará luego y con la mayor eficacia en ese Partido una recoleccion de cuantos caballos serranos y yequas mamas hubiese en él, mandandome una relacion nominal de sus dueños con expresion de sus precios, que procurará sean equitativos, para providenciar su pago.

$\mathrm{Si}$ los animales que le remitiese dicho Subdelegado de Lucanas llegasen despues que hubiesen pasado los dos Escuadrones que primero deben .venir, los retendrá ahi haciendolos mantener hasta que se dizponga de ellos.

Dios gue. à V. m. a. Cuzco 14 de noviembre de 1822 .

(Ido.) José de la Serna

(una rúbrica)

Sr. Subdelegado de Andahuailas.

(L. I, No 16) 
Es necestrio que desde luege proneda $V$. al enbargo de todos los difares (sie) proximos e in:nediuto: i la:; rascinass que en e! part:do del inando de $V$. hiciercin ultiratiente lue dos Ciserpos de Caballeria procedentes de los Valles de lauia y que en les inienus pascanas se hagan acopios de granos como para seiscientos caballos, que es decir treinta y cinco fanegas en sada une. A. los jueños de Alialiares enbur. gados los hara $V$. responssabies de su conserbacion y cuidado y paro mi conccimiento rne remitirs V. una ruson cie los que se embarcaren y sus precios, expresando el estado en que se halle la alfalfa y para cuando estara madura.

Dics gue. á V. m. a. Cuzco Enero 1\%/823.

(tdo.) José de la Serna

(una rúbrica)

Sr. Subclelegada de Andahuayles.

$$
\text { (L. III, N: I) }
$$

En el dia de mañana sale do esta Carjital ol Subiente de! Batalier de Burgos D. Canilo Gonzales conducirndo osho cargas, cuatrc de ellas con dinero y cuatro con bestuazics. Satistecho por estas Cajas Núcionales el leguaje por la posta hasta ese nunto, asi de dhas. carças como de las tres mulas de Silla que be ocupando una para si y dos para los dos Dragones que lleva de esco!ta y el del resteso de es tas tres úlitmas, de inodo árecno tiene V tua básarlo ni al oficial ni á dhos. dos Dragones. Estos ultimosi regresaian de ese nunlo püra esta Cpital, y el mencionado Subteniente Gonzales pasaria con los referidos ocho cargas hasta Fiumanga facilitandole V. sin demcra las Mulas necesarias para ellas y para su Silla.

Al Comandante de ese Deposito orden que !és cargas han de pa. sar con la competente escolta si fuese posible montada esta, y en este supuesto hará $V$. el mayor esfuerzo para proporcionarles las bestias necesarias que esten en verdadero estado de hacer la marcha de ida y buelta.

El Oficial no ba satisfecho del flete de su mula de silla si no de ida y regreso á ese punto, y no desde ese a Huamanga, que serrira a $\mathrm{V}$. de govierno.

Dios gue. á V. m. as. Cuzco enero $1^{\circ}$ de 1823.

(fdo.) José de la Serna

(una rúbrica)

Sr. Subdelegado del Partido de Andahuaylas. 
He recivido el pliego del Comandante Militar de Lucanas que V. me ha incluido en su oficio $N^{9} 111$; y al mismo dirijira sin perdida de momentos el adjunto para extraordinarios que sean trazadios y de confianza.

También dirijira V. por extraordinario el otro pliego que le incluyo para el Sr. Gele Politico de esa Provincia y del recibo y remision de ambos me dará aviso.

Dios que. á V. m. a. Cuzco Enero 4 de 1823.

(ido.) José de la Serna

(una rúbrica)

Sr. Subdelegado del Partido de Andahuaylas.

(L. III, No 3)

He recivido los tres pliegos que me ha remitido $V$. con su oficio N: 113 y sin perdida de momento dirijira V. el adjunto al Subdelegado interino del Partido de Lucanas.

Dios gue. a V. m. a. Cuzco Enero 19 de 1823.

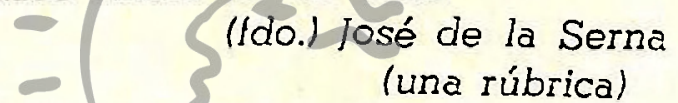

Sr. Subdelegado del Partido de Andahuaylas.

(L. III, No 4)

Dirigirá $V$. por exträordinarios iratados $\mathrm{Y}$ de confianza el adjunio pliego para el Sr. Gefe Político de Ifuamanga, dánaome aviso de haberlo asi verificado.

Dios G.uarde a V. m. a. Cusco, enero 25 de 1823.

$$
\begin{aligned}
& \text { (fdo.) José de la Serna } \\
& \text { (lina rúbrica) } \\
& \text { (L. III, No 5) }
\end{aligned}
$$

Disponga V. que e! adiunto pliego se dirija al Sr. Gefe Político e Intedente Interino de Fiuarnanga con extraordinario tratados y de toda confianza, y que del nismo modo remita al Comandanie Militar de Iucanas Don Cayetanc Aballe el que para el bá roiulado, dándor:e aviso de la prontitud con que esta orden queda executada.

Dios g. á V. m. a.

Cusco enero 29 de 1823.

(Ido.) José de la Serna

Sr. Subdelegado del Partido de Andahuaylas.

(L. III, NQ 6) 
A! Sr. Gefe Político Intendente Interino de Guamanga digo con esta misiva lo que sigue.

Hoy ha salido de esta Can:ta! el Primer Butallón del Rergimeinto de! Infante, y para esa en donde llegará el 13. Las jornodas que debo hacer en el Territorio de !a Provincia de mando del Oficial son en Huancarama, en donde estará el 4, e! 5 Pircos. el $€$ Andoguailas, el 7 descanso en este último punto, el 8 en Mollebambis, $\Theta$ ! 9 en Chincheros, el 10 a media legua antes de llegar a la Hacienda de Yrias, el 11 en lugar de ir á Matara, dejeáa ir á un pueblecito que dicen se hálla a un lado de aquella, e! 12 en Tarnbil!o, y al 13 en eso Cilidad.

"En conseruencia dispondrá $V$. oure en las pascanas que dejo marcadas, se pongan todos los aucilics necesúrios de víveres, leña y demás. con conceplo de 260 piazas de que consta disho Batallón, á fin de que se eviten perjuicios y veiárnenes con los Pueblos que son consiguienies en el paso de trcpas por diciplinacles que sean, cuando no encuentran los recursos necesirios para su subsistencia; así repito al Oficial de mis órdenes terminantes para que apronten los aucilios; en el concepto de que para ganar tiempo trascribo en derechura esta orden al Subdelegado de Andaguailas".

Lo que traslado a $V$. para su inteligenzia y puntual cumplimiento, con especial encargo de que se apronten los aucilios indicados, a fin de que no haya reclamaciones, ni por parte de las tropas, ni por las habitantes del Parlido de sut mando.

Dics gue. à v. m. a. Cusco enero 29 de 1823.

\author{
(f́clo.) José de la Serna
}

(una rúbrica)

Sr. Subdelegado de Andoguailas.

(L. III, No 7)

Quedo enterado de que e! Subảelegado del Partido de Aymaraez, ha entregado á $V$. la cantidad de once mil seiscientos dose posos seis r. del ramo de contribuciones de su carço, y prevengo a V. que se conserven sin tocaree $\dot{d}$ un peso, para que unidos al contingente que deve salir de esta Ciudad dentro de breves días, se remitan a Huancayo para la subsistencia de las tropas de operaciones. 
Lo digo a V. en contestación a su Oficio No 125, quedando enterado de que remitio al Sr. Gefe Politico int?. de Huancayo el pliego de que trata.

Dios que. à V. rn. a. Cuzco Feb! 19 de 1823.

Sr. Subdelegado da Andaquailas.

\section{(fdo.) José de la Serna (una rúbrica)}

$$
\text { (L. IV, No 1) }
$$

Conido. en 15 de dho. Con tha. 24 de Enero ultimo prebine á V. que las Dos mil varas de Tucuyos (sic) que condujo el Capitan Tacorena á ese punto remitidas por el Sor Gefe Politico into de Huamanga las embiase desde luego intactas a esta Capital, y no habiendo tenicio comiestacion ni aviso de que las haya mandado, se lo repito de nuevo para que si al recivo de este no lo huviese verificado, realise la remision luego, luego.

Dios gue. á V m. a. Cuzco 10 de Febrero de 1823.

Sr. Subdelegada de Andahuaylas.

(fdo.) José de la Serna (una rúbrica)

\section{Biblioteca de Letras. IV, № 2)}

He recivido e! pliego que me haineluido Q? en sú oricio num" 128, y el adjunto para el Comandante Militar de Lucanas y Parinacochas dispnodrá $V$. que lo conduzca luego un estraordinario trotador y de confianza, también quedan en mi poder los demás pliegos.

Dios gue. ó V. m. a. Cuzco 13 de Febrero de 1823.

$$
\begin{gathered}
\text { (fdo.) José de la Serna } \\
\text { (una rúbrica) }
\end{gathered}
$$

Sr. Subdelegado de Andaguailas.

$$
\text { (L. IV, No 3) }
$$

El Día 1o del proximo Marzo empiezan á salir de esta barios Cuerpos con destino al Valle de Jauia, el $1^{0}$ será el de Dragones de la Union compuesto de tres Escuadrones con 600 Cavallos, y los aviso á V. con anticipacion para que en el Partido de su cargo se apronte lo nesesario para hombres y cavallos. 
El 2 seguira uno de Ynfunteria, $y$ asi susesivamie. en la inteligencia que ninguno de estos Cuerpos baxara de 800 plazas; asi prepare V. las que ninguno de estos Cuerpos baxará de 200 piazas: asi prepare V. la carne $\gamma$ demas pata durtes le racion que est. detaliadu, pues no es justo. que estas balientes tropas carescan de cuinio nesestien.

Dios gue á V. m. a. Cuzco 17 de Febro. de 1223.

Sr. Subdelegacio de Andarsuailize.

\section{(ído.) José de la Sema \\ (una rúbrica)}

$$
\text { (L. IV, N"4) }
$$

Sa.e en esle dia dn. Marcelino Iierrera conduciendo 12000 pesos cliyo ariso anticifo a $V$. paru gue al pasar por ese punto le entregue los 1512 pesos o rejles cive resibicí del Subdelecjado de Aymaraes y previne á $V$. se conservasen con este objeio en mi orden del 10.

Si el Co.riandte. la Fuente huviere regresado de Humanga, facilitará una partida de 3 ó 10 Soldados de toda confianza para que escolten el contingente $y$ vayetones gue conduce Herrera hasta el puente de Pampes; $y$ de no dispondrá $V$. que en su defecto acornpañen al conductor el mismo num ${ }^{\circ}$ de hombres armados ó los que $V$. jusgue nesesarios para la secguridad de ia conduccion, hasta el mismo Puente, desde donde será escoltadà por lunal partida Cque debe enviai al electo el Sor. Gele Politico Yntendte joteris:o dechluanángan qu quien trascribo ésta orden al intento.

Díos que. á V. m. a. Cuzco 17 de Febrero de 1823.

Sor. Subdelegado de Andahuailas.

$$
\begin{aligned}
& \text { (ido.) José de la Serna } \\
& \text { (una rúbrica) }
\end{aligned}
$$

$$
\text { (L. IV, N" 5) }
$$

Contestado en

A pesar de quanto prebine á $V$. en mi orden de 25 de dho. mes. 17 del actual, le ordeno de nuevo que el ultimo contingente que conduce don Marcelino Herrera se detenga en ese punto hasta que llegue a él el Comandante Labraque que sale mar̃ana de esta ciudad conduciendo reclutas, corı el qual deberá hir (sic) el conductor del contingente y de los efectos que lleva, a fin de que los treinta hombres que lleva Labraque de esta guarni- 
cion puadan regrosar desde al puente de Pampas, repito con esta fecha al Scr. Gefe Politico interno de Huamanga mande á aquel punto la correspondiente esco!ia quo debe hallarse en el Puenie para el 3 de Marzo próximo, y al efecto hará $V$. pasar el adjunto pliego ganando horas a! Sor. Gefe Politico de Hiuamanga.

Díos gue. á V. m. a. Cuzco 19 de Febrero de 1823.

Sor Subdelegada de Andahuailas.

(fdo.) José de la Serna

(una rúbrica)

(L. IV. N! 6)

ademas de los cuarenta reclutas se remitirán a esta todos los demas que enbie el Comante. Aballe.
Los cuarento reclutas que el Comandante Abalio pariicipa haber salido el 12 del actual para ese punto con el Capitan Carmona, dispondrá V. so remitan a esta Ciudad con la primera partida que benga para esta Capital.

Dios gu. á V.m.a. Cuzco 19 de Febrero de 1832.

\section{Biblioteca (fdo.) José de la Serna Tuna rúbrica)}

Sor. Subdelegado de "Andahuailas.cinelli Converso"

$$
\text { (L. IV, NQ 7) }
$$

Contestado en 25 del mismo.
Se hán recivido los tres pliegos de que trata el Oficio de V. numo 132, y remito el adjunto para que sin la menor detencion lo dirija al Sor. Gefe Politico Yntendente interino de Huamanga, $y$ el otro al Comandante Aballe.

Dios gue. á V. muchos años. Cuzco 19 de febrero de 1823.

(fdo.) José de la Serna (una rúbrica)

Sor Subdelegado del Partido de Andaguailas.

(L. III, No 8) 
Quedio enterajo de gue e! Arriero Ynocencio Vera conducia las mil varas de tucuyo (sic) à esta Capita! y que la ocurrencia de Abancay ha hecho que ya no esté aduuí e! tucuyo como igualmente quo en consecuencia de haver $\%$ dispues!o se is devolylesen lus mulas a Vera $y$ regresase, no tardará de liegar á esta Capital. Lo digo a V. en contestacion a su oficio numero 133.

Dios gue. a $V$. muchos áros. Cuzco 19 de Febrero de 1823.

(fdo.) José de la Serna (una rúbrica)

Sor. Subdelegado de Andahuailas.

(L. III, No 9)

El oficio de $V$. numero 142 me instruye de haver dado direccion a los pliegos que le dirijí en 19 del actual para el Sr. Gefe Político de esa Provincia y el Comandante Militar de L.ucanas y Parinacochas; igualmente he recivido los que me ha incluido en su citado oficio del Comandante Aballe.

Dios gue. á V. m. a Cuzco, 28 de Febrero de 1823.

\section{(fdo.) José de la Serna}

Sor. Subdelegado Bde Andahuálas.de Letras" (uná rúbrica)
"Jorge Puccinelli Converso" $\quad$ (L. II, N" 23)

Quedo enterado de quanto me previene en su oficio No 140, y apruevo su determinacion de que con los 30 hombres de esta Guarnicion continuen la marcha los reclutas que conduce Vidal.

Dios gue. á $V$. m. a. Cuzco 28 de Febrero de 1823.

\section{(tdo.) José de la Serna}

(una rúbrica)

Sr. Subdelegado de Andahuailas.

$$
\text { (L. IV, No 8) }
$$

Esta bien que practique $V$. las diligencias para el acopio de viveres, granos y forrajes para los Cuerpos de Ynfanteria y Caballeria que luego emprenderan la marcha con direccion al Quartel gral. en Huancayo; esperando desplegará $V$. todo su zelo para que no falten estos auxilios á tan benemeritas tropas y que proporcionará el número de fa- 
negas de Maiz en lás pascinas destinadas pues para que reciban las raciones en las cantidades que estan detalladas.

Digame V. el nombre del Alcalde y de los Yndios que se lleva el Comandante del Ynfante en clase de reclutas; y afin de que en lo sucesivo no se repitan los excesos que $V$. me manifiesta he tomado las providencias convenientes.

Dios gue. a V. m. a. Cuzco Mzo. 2/823.

(íclo.) José de la Serna

Sr. Subdelegado de Andahuailas.

(una rúbrica)

$$
\text { (L. III, No 10) }
$$

He recivido el Pliego del Sor. Gefe Politico Yntendte. into de esa Provincia que me incluye en su oficio numero 138 que dejo contestado.

Dios gue. á V. m. a. Cuzco Marzo 2 de 1823.

Sor. Subdelegado int' de Anciahuailas.

$$
\text { (tado.) José de la Serna }
$$

(una rúbrica)

$$
\text { (L. III, No 11) }
$$

El 7 saldran de aquí treinta cargas de Efectos para Huancayo, y lo aviso á V. para que tenga prontas treinta y cuatro Mulas para el 16 á fin de que no se demoren, pues urge lleguen sin demora al Egto.

Dios gue. á V.rmoag Cuzco 2 del Marzondell823.

$$
\text { (fdo.) José de la Serna }
$$

(una rúbrica)

Sr. Subdelegado del Partido de Andahuaylas.

$$
\text { (L. III, } N^{9} \text { 12) }
$$

Mañana salen de esta Capital con destino al Exto. de Huancayo treinta cargas de Pertrechos de Guerra, y le anticipo este aviso para que á su llegada á esa tenga $V$. prontas igual numero de Mulas, y que sin la menor demora continue el que ba (sic) comisionado de ellas hasta Guamanga.

Dios gue. á V. m. a. Cuzco Mzo. 7/823.

$$
\begin{gathered}
\text { (fdo.) José de la Serna } \\
\text { (una rúbrica) }
\end{gathered}
$$

Sr. Subdelegado de Andahuailas. 


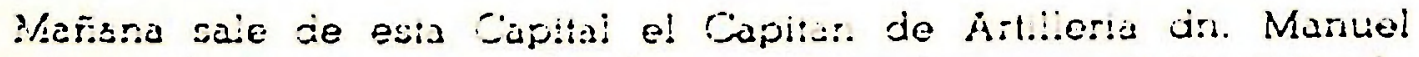
Gülado conduciendo carcjus de plata y vestiartos para el Egercito do Zunncayo, y dispondré $V$. Gi: stn demora se le aironten veinie mu. las de carga, en relovo je ctras lantas aue leva de esta Capital per:er:ecientes a ese puebio, paris gue continue su marcha lusia Huamanca.

Dios gus. á V. n. a. Cuzco 14 de iharzo de 1823.

(fdo.) josé de la Sernu

(una rúbrica)

S. Sucdelegacio die inciahuailas.

$$
\text { (L. III, NQ 14) }
$$

Quezic impuesto de si selo sn haber hecho pasar sin demora á Iuarnanga las treinta carges de utiles gue conducta el cabo de Artillor:2 Francisco Valentin, y en espera cen velnte riulas al Oiicial dol mismo cuepo Ga!:ndo, para que continue su marcha sin tardanza con las. cargas de vestuario y plala que lleba á su eargo.

Lo digo a $V$. en coniestacion á su oficio numero 146.

Dios sue. á V. m. a. Yucay 26 de Marzo de 1823.

Sr. Subdelegado de Andahuáilàs.

\section{Biblioteca deido.t tose de la Serna "Jorge Puccinelli Conve fura rúbrica)}

(L. II, N? 24)

Con el Ofirio de $V$, he recibido el pliergo del Comandante Militar cie Lucanas, $y$ remito al exjunto para que $V$. se lo dirija desde luego.

Díos gue. á V. m. añs. Yucay 26 de Marzo de 1823.

Sr. Subdelegado de Andahuailas.

(fdo.) José de la Serna (una rúbrica)

(L. III, N' 15\%

en 2 de $\mathrm{Abl}$. contestado
Digame $V$. quien traia el Tocuyo que se remitia de Humanga, que dia salio de esa Villa, con que Mulas, con esprecion de los nombres de todos, á fin de que se indague el paradero del dicho Tocuyo, pues. 
to que suando no se tiene noticia de él á la fha. es de recelarse haya padecido extravio.

Dios que. á V. m. a. Yucay 26 de marzo de 1823.

Sr. Subdelegado je Andahuailas.

(fdo.) José de la Serna

(una rúbrica)

(L. III, No 16)

En concecuencia de lo que $V$. me expone en su Oficio n. 147 resuelvo, que asigne un corto prest á treinta Milicianos acuarteladas, los cuales deberán estar al cargo de un Oficial zeloso (sic), activo y desidido por la causa de la Nacion, pudiendo V. confiarle desde luego la comision avisandome la persona que nombre y teniendo entendido de que esta orden es provisional y mieniras no se determina otra cosa, y que los Milisianos acuartelados deben ser de toda confianza.

Dios rjue. á V. in. a. Yucay 2E de Marzo de 1823.

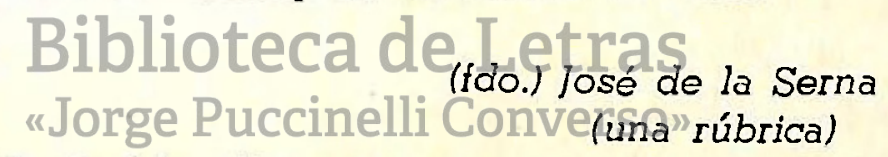

Sr. Subdelegado de Andahuailas.

(L. III, N $N^{17)}$

Con el Oficio de $V$. de 25 del actual he recibido el Pliego que en el me incluye, y le remic el adjunto para que lo entregue al Ver. Comte. de Cazadores, a quien lo socorrera V. con las cantidades que le sean posibles, las cuales le serán avonadas por el Ministerio de Hacienda de Guamanga en sus cuentas.

Dios gue. á V. m. a. Yucay Marzo 30 de 1823.

(fdo.) José de la Serna

(una rúbrica)

Sr. Subdelegado de Andahuailas.

(L. III, No 18) 
scristegiacio on if do Ab!.
Yrmediatamente que :ecies V. el adjunto pliogo lo jirigira por extrao:dinurio al Comandante Miliss de Lucanas.

Lios guo á V. ri. a. idarzo 30 de 1823.

(ido.) José de la Sornu (una rúbrica)

E:- Subcielogado do Andüzuailas.

$$
\text { (L. III, N! 19) }
$$

Mañana sale del Cuzcc e! Tonierte de h Guurnicion Dn. Nicolas Vidäl con dos Artillercs conduciendo veinte y cautro cargas de Paroue hasta Huamanga, $y$ lc aviso a $V$. para su conscimiento, y a fin de cue desde luego vaya árontanclo el relevo de las 24 cargas, para que $V$ idal no encuentre delención en ese punio d su liegada.

Dios gue. á V. m. a. Yucay. 31 de Marzo de 1823.

(fdo.) José de la Serna (una rúbrica)

S:. Subdelegado de Andahuailas.

\section{Biblioteca de Ietras (L. II, N! 25)}

Ytinerario de la Jutg guldeberan Eergiveloso Butallones de Gerona y el Centro desde el Cuzco á Huancayo.

\section{PUEBLOS}

Del Cuzco á Anta

A Surite

A Lima-tambo

A Mollepata

A Curahuasi Ydem

A. Abancay

A Guancarama

A Pincos

A Andaguaylas

Ydem

A Mollebamba

\section{GERONA CENTRO}

\begin{tabular}{ll}
\hline 4 & 4 \\
3 & 3 \\
6 & 6 \\
4 & 4 \\
8 & 8 \\
$" 1$ & $\ddot{7}$ \\
7 & 8 \\
8 & 3 \\
3 & 5 \\
5 & 4 \\
$" 1$ & 4
\end{tabular}


A Chincheros

A la Casa de Ivias

A Matará

A Tambillo

A. Huamanga

Ydem

A Huanta

A Marcas

A Acobamba

A Pucará

A Buyaromachay

A Picoy

A Yscuchaca

A Nahuinpuquio

A Huancayo

Total

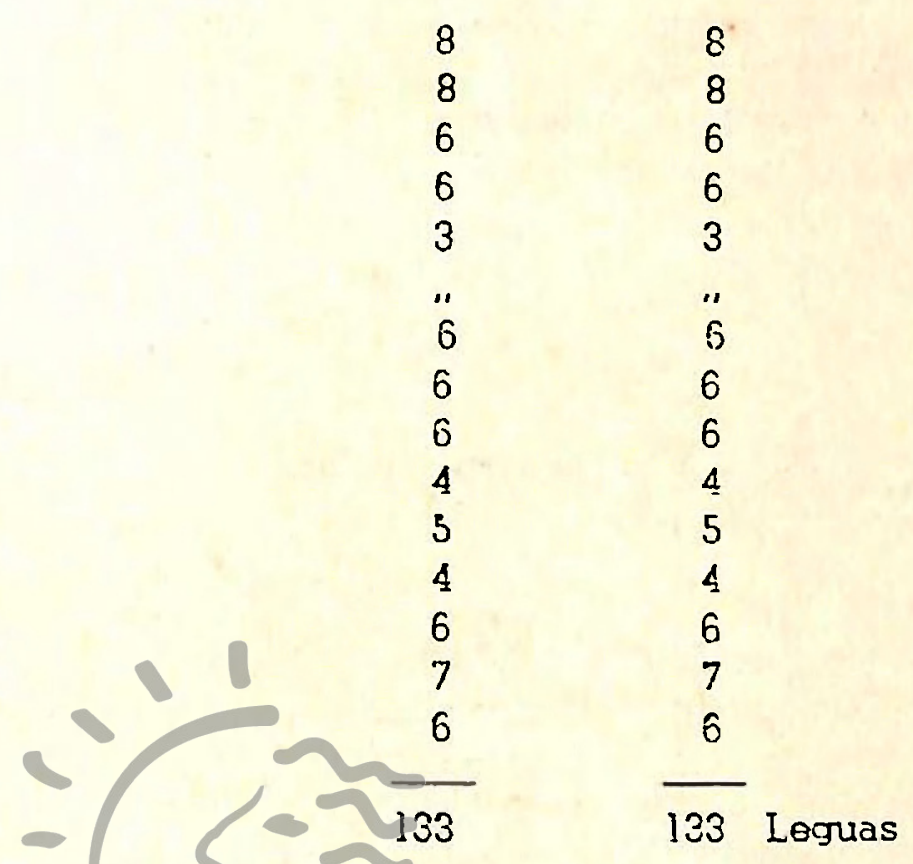

Nota: Desde Yvias se tomará el camino de la izquierda por los altos sin entrar en Ocros, que es mas derecho y mas llano para llegar á Matará.

\section{Yucay 15ide Aabiedel 1823. Letras}

(fdo.) Eulogio de Sta. Crijz.

(una rúbrica)

(L. IV, Nค 9)

Quedo enterado de la pronta y segura dirección que dio $V$. á los pliegos que en el me cita para el Comandte. Aballe y Subdelegado de Parinacochas $y$ he recivido el que me acoispaña de este ultimo.

Apruebo la determinacion de V. en la nueba bista que dá a los pliegos por manos del Cura de Larcay consultando en esto su seguridad y menos gastos de la Hacienda Nacional segun me manifiesta en su Oíicio n. 171 que contesto.

Dios gue. a V. m. a. Cuzco julio 10/823.

Si. Subdélegado de Andahuailas.

\section{(f́do.) José de la Serna} (una rúbrica)

(L. III, NO 20) 
نe recibido e! pl:egc de! St. Gele Político Intendente do Huamaig) o.e me incluye $V$. con su oficio número 177. estando bien que a su conductor lo haya socorrido con veinie $y$ cuatro pesos. para el pa. zo de las postas de benida, regreso y gralificción.

Dics gue. a V. m. a. Cuzco 11 de Julio de 1823.

$$
\begin{gathered}
\text { (ido.) José de la Serna } \\
\text { (una rúbrica) }
\end{gathered}
$$

Sr. Subdelegado de Andahuailas.

$$
\text { (L. II, No 26) }
$$

Por el Oficio n": 178 he recivido e! piliego que en e! the inciuye.

Quedo impuesto de que bavia arbitrado todos los medios condu. cantes para el establecimiento de postas en la Vista que le ha prevenido el Exmo. Sor. Gral. en Gele del Exlo. de Lima, y que al instante que recivio el Voletin relerente a la entrado de aquel en aquella anti gria Capital hizo publicar por bando tan importante $y$ satisfacloria noticia para satisfaccion de esoz lieles havitartes.

Díos gue. á V. m. a. Cuzco 16 de julio de 1823.

\section{Biblioteca defido.f tose de la sorno "Jorge Puccinelli Convefuna" súbrica)}

Sr. Subdelegacio de Andühuailas.

(L. III, N!21)

He recivido el Paquele grande forrado en Yndiana $Y$ otro sencillo del Comandandte. Militar de Lucanas á que se reliere $V$. en su Oficio n" 180 remitido por extraosdinario que há regresado on este dia.

Díos gue. á V. m. à. Cuzco 16 de Julio de 1823 .

(fdo.) José de la Serna

(una rúbrica)

Sr. Subdelegado de Andahuailas.

(L. III, NO 22) 
Hará V. que sin detencion alguna continuen los catorce fuciles Yngleses que por su conducto y disposicion mia remite á esta Capital el Sor. Gefe Politico into de esa Prová.

Dios que. á V. m. a. Cuzco 16 de Julio de 1823.

Sr. Subdelegado de Andahuailas.

\section{(fdo.) José de la Serna \\ (una rúbrica)}

Disponga $V$. se remitan a Abancay treinta ó cuarenta Milisianos que deberún estar alii el 30 del actua! en donde recibirán ochenta reclutas y los conducirán á Andaguailas en cuyo punto descansarán un dia y se llebaran al Puente de Pampas para que los reciba la Partida que de Huamanga debe embiar el Sr. Gefe Pclítico de la Provincia; para cuyo efecto y el de que desde el puente lleguen á aquella ciudad le pase la orden compelente en el adjunto pliecgo que $V$. le remitirá desde luego por Estraordinario.

Dios que. á V. m. à. Cuzco, Noviembre 21 de 1823.

\section{Biblioteca detdod José cie la Scma} sr. Subdologado de Jarge Puiccinelli Conver'SOn "úorica)
(L. II, No 27)

Ynmeditamente que reciva V. esta, remitirá á Huamanga los adjuntos pliegos, con una persona de sil confianza y trotadora, pues asi interesan al Servicio Nacional; dandome cuenta de su cumplimiento.

Dios gue. á V. m. à. Cuzco, Noviembre 24 de 1823.

(f́do.) José de la Serna (una rúbrica)

Sr. Subdeleqado de Andahuaitas.

(L. II, No 28)

Desde luego dispondra $V$. que en el distrito de su jurisdiccion se apronten los viveres $y$ demas necesario para el Batallon del Centro, 
Tue an la fuerza de ocho sientas cinquenta piazas saidrá de esta ca. Fital ei 28 del actual a incorporarse al Exterior cie! Norte. preparando aquellos er las Pascanas que han acostumitrado hacer los cuerpos de Ynfanteria, $y$ arreglandose para las cantidades a lo detallado anteriormente.

Del reciko y cumplimiento de esta orden me dará $V$. aviso.

Dios gue. à V. m. a. Cuzco, Noviembre 24 de 1823.

Ifdo.l José de la Serna

Sr. Subjelegracio de Andahuailas.

(unà rúbrica)

(L. II, N? 29)

Noviembre 30 Suriti.

Diciembre 1? Limatamio

1. Mollepata

3. Curahuasi

4. Abancay

5. Id. descanso

6. Guancarama

7. Tarama

2. San Geronimo

9. Andaguailas.

Pasado mañañ Saldrán de esta Capital Ciento cincuenta Caballos con destino al Exterior del Norte. El oficial que sale de aqui con ellos será relevado en el Puente de Pampas por otro que ha de mandar el Exelentísimo Sr. General Canterac, y V. dispondrá desde luego que en las pascanas marcadas al margen correspondientes a su jurisdiccion se apronten los forrages necesarios sin que por excusa ni pretexto alguno haya la menor falta quedando $V$. responsable al exacto cumplimiento de esta orden.

El 19 de Diciembre y no el 28 del actual como dije á $V$. en $\mathrm{mi}$ oficio de 24 saldrá del Centro con la fuerza de nove- 
cientas plazas llevando la ruta que acompaño $\mathrm{y}$ en esie supuesto dispondrá V. el apresto de viveres en las pascanas que aquella expresa.

Dios gue. á V. m. a. Cuzco Noviembre 27 de 1823.

Sr. Subdelegado de Andahuailas.

\section{(fdo.) José de la Serna}

(una rúbrica)

$$
\text { (L. II, NN 30) }
$$

Facilitará V. sin la menor demora á D. Fernando Salas Guerrero que hoy sale de esta Capital conduciendo el contingente á Huarranga, cinco Mulas de carga y una Silla para que continúe la marcha. Respecto aquelas que lleva pertenecientes al Arriero Julian Sante Segarra deven regresar desde ese punto hasta el Cuzca, ban pagados a razon de ocho peses cada una; debiendo V. dar a Guerrero la escolta competente que consulte la seguridad del contingente en su transito a Huamanga.

Los dos Dragones que jam de aqui regresaran tambien desde ese punto.

Dios gue. á V. m. a. Cuzco, Noviembre 27 de 1823.

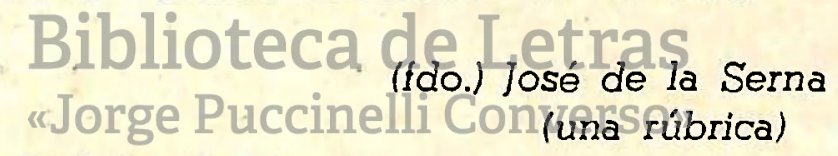

Sr. Subdelegado de Andahuailas.

(L. II, No 3I)

El adjunto pliego interesante al servicio nacional lo dirijirá $V$. inmediatamente por extraordinario al Sor. Gefe Político é Intendente de esa Proincia y de haverlo asi verificado me dará $V$. partes.

Dios guarde a V. m. a. Cuzco Noviembre 28 de 1823.

(fdo.) José de la Serna

(una rúbrica)

Sor Subdelegado interino de Andahuailas.

(L. I, No 17) 